\title{
The mechanical properties of 1060 aluminum joint by continuous drive friction welding
}

\author{
Qingzhe Li ${ }^{1}$, Ranfeng Qiu ${ }^{1,2}$, Zhongbao Shen ${ }^{1}$, Longlong Hou ${ }^{1}$, Lihu Cui ${ }^{1}$ \\ 1.School of Materials Science and Engineering, Henan University of Science and Technology, \\ Luoyang, 471003, China \\ 2.Collaborative Innovation Center of Nonferrous Metals,Luoyang471003,China
}

\begin{abstract}
KEYWORD: Friction welding, Aluminum, Mechanical properties
ABSTRACT: Pure aluminum was welded by friction welding in this study. Friction welding of pure aluminum was performed in the fixed upset pressure and friction pressure respectively. The tensile strength of joints was measured. According to the studies performed, pure aluminum welding effect of welding parameters on the tensile strength, friction pressure and upset pressure are the $3.5 \mathrm{kN}$, the maximum tensile load of the welded joint, joint strength, $29.1 \mathrm{kN}$. Parameter influence on deformation of joints, pressure and friction presses increase, such that the displacement increases, excessive wear and flanging on the adverse effects on material properties. The results have revealed a successful joint. Therefore pure aluminum in friction pressure is $2 \mathrm{kN}$, upset pressure is $2 \mathrm{kN}$, friction is $2.5 \mathrm{~s}$, can get sound joint.
\end{abstract}

\section{INTRODUCTION}

Aluminum was discovered in the early 19th century, beginning in 1880 as a high-priority light weight metal to further applications. Aluminum and aluminum alloys are extensively used in various industries. Aluminum has a significant advantage due to its active chemical properties [1]. Its main advantages include higher regenerative ability, light weight, larger linear expansion coefficient and good formability, as a chemically reactive metal, but easily oxidized in air. Thermal conductivity of aluminum and aluminum alloys and the specific heat capacity is relatively large. Such as spot welding, friction stir welding and so on can be used for welding aluminum and its alloy, but the adaptability of different welding methods is difference. Various welding methods have their own applications [2]. However, there are few reports on friction welding of aluminum alloy.

Friction welding has gained importance in the fabrication industry. The advantages of this process include high reproducibility, short production time and low energy input [3]. This unique method of joining materials is achieved by rotating one component at high revolutions per minute in contact with a second motionless component. By applying axial pressure during rotation, the temperature at the interface is increased until the materials reach the plastic state. At a precise moment, the rotation is stopped and axial forging force is then applied between the two components. The combination of pressure and heat forges a solid state bond at the interface of the two joining parts [4]. The process can be carried out using conventional friction welding apparatus but under a protective atmosphere to avoid metal oxidation.

In this study, the friction welding of aluminum is investigated by method without using any interlayer and in different friction pressure and upset pressure. The mechanical properties of joints were analyzed.

\section{THE EXPERIMENTAL PROCEDURE}

The dimensions of aluminum rods used in this study were $\Phi 14 \mathrm{~mm} \times 145 \mathrm{~mm}$ and $\Phi 14 \mathrm{~mm} \times 125 \mathrm{~mm}$, respectively. The chemical compositions and tensile strength of aluminum material used is given in table1. Welding schematic shown in Fig.1. Experimental set up was designed and constructed to apply the continuous drive friction welding method. A continuous drive friction welding machine was employed throughout the experiments. In the continuous drive friction method, one of the components 
is held stationary while the other is rotated at a constant speed. The two components are brought together under axial pressure for a certain friction time. Then, the clutch is separated from the drive, and the rotary component is brought to stop within the braking time while the axial pressure on the stationary part is increased to a higher upset pressure for a predetermined upset time. A 4Kw motor drive with rotational speed $2000 \mathrm{r} / \mathrm{min}$ was used. The welding time is $2.5 \mathrm{~s}$. Welding condition was used in the friction welding experiments are given in table 2. In order to examine the mechanical properties of the joints, the tensile-shear tests were performed under a cross-head velocity of $1.0 \times 10^{-5} \mathrm{~m} / \mathrm{s}$ at room temperature.

Table 1 Chemical composition (mass \%)

\begin{tabular}{ccccccc}
\hline $\mathrm{Mg}$ & $\mathrm{Al}$ & $\mathrm{Si}$ & $\mathrm{Fe}$ & $\mathrm{Cu}$ & $\mathrm{Mn}$ & $\mathrm{V}$ \\
\hline 0.03 & Bal. & 0.25 & 0.35 & 0.05 & 0.03 & 0.05 \\
\hline
\end{tabular}

Table 2 Conditions used in the friction welding experiments

\begin{tabular}{llll}
\hline $\begin{array}{l}\text { Sample } \\
\text { number }\end{array}$ & $\begin{array}{l}\text { Welding } \\
\text { time } / \mathrm{s}\end{array}$ & $\begin{array}{l}\text { Friction } \\
\text { pressure/kN }\end{array}$ & $\begin{array}{l}\text { Upset pres- } \\
\text { sure/kN }\end{array}$ \\
\hline 1 & 2.5 & 3.5 & 3.5 \\
2 & 2.5 & 3.0 & 3.5 \\
3 & 2.5 & 2.5 & 3.5 \\
4 & 2.5 & 2.0 & 3.5 \\
5 & 2.5 & 2.0 & 3.0 \\
6 & 2.5 & 2.0 & 2.5 \\
7 & 2.5 & 2.0 & 2.0 \\
\hline
\end{tabular}

\section{RESULTS AND DISCUSSION}

In many studies related to the solid-sate bonding of dissimilar materials, with the change of friction and upset pressure, the tensile strength presents certain rules [5]. The continuous-drive friction welding method is one of the side is fixed while the other is rotated at a fixed speed. After a certain friction time under the upset pressure the two ends brought together. So this paper studies the above two parameters that affect the joint tensile strength. Welding in the process of using a single variable method respectively in fixed upset pressure, changing the friction pressure get the changes in the maximum load; then fixed friction pressure, changing the upset pressure get the changes in maximum load, thus to analyze different parameters on the effect of welding joints tensile strength.

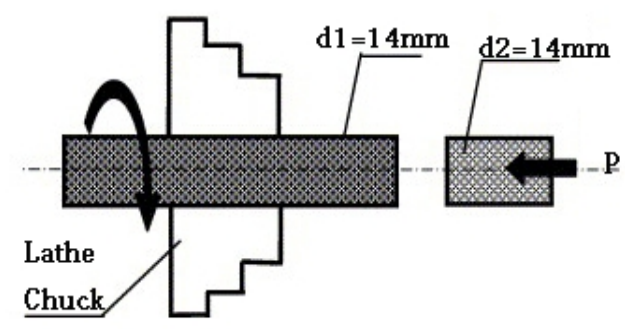

Fig.1 Welding schematic 
As show in the Fig.2, we can see the tensile strength with increasing friction pressure welding generally showing an increasing trend. Due to the gradually increasing the friction pressure, the material deformation under the action of frictional heat, the amount of deformation of the base material increasing so that the contact surface migration of metal particles occurs, so we can get the reliable bonding. When friction pressure is changed from $2.5 \mathrm{kN}$ to $2.0 \mathrm{kN}$, the load not fall but rise, this may be due to the lower friction pressure, welding parts contact surface overheating decreases, although the heat deformation decreased, but the stability of the base metal mechanics not easy to lose, so the tensile strength of joints is high. When the friction pressure changed from the $2.5 \mathrm{kN}$ to $2.0 \mathrm{Kn}$, the maximum load is gradually increased. Friction pressure has a great influence on the quality of welded jointed. In order to generate enough friction heating power, ensure full contact with the surface of the friction, friction pressure can not too small. This is due to the enough friction heating power produced, formed a reliable bonding.

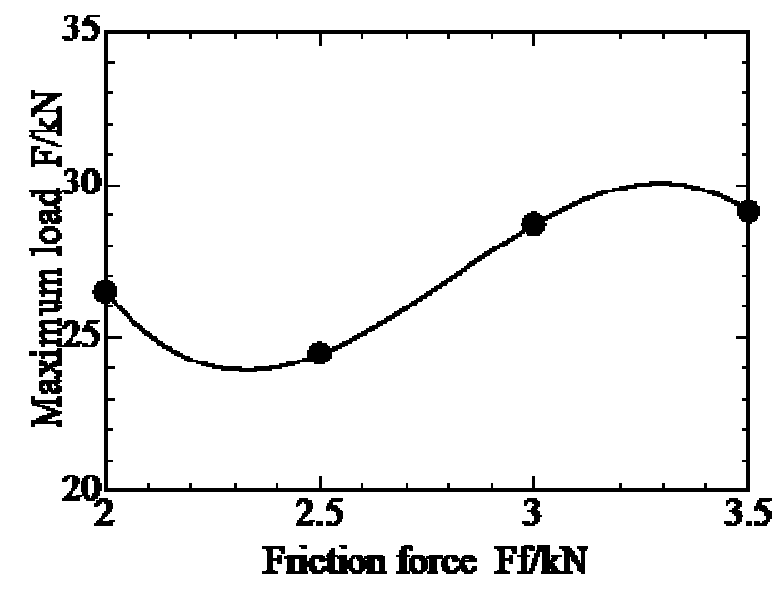

Fig.2 Relation between tensile strength and friction pressure

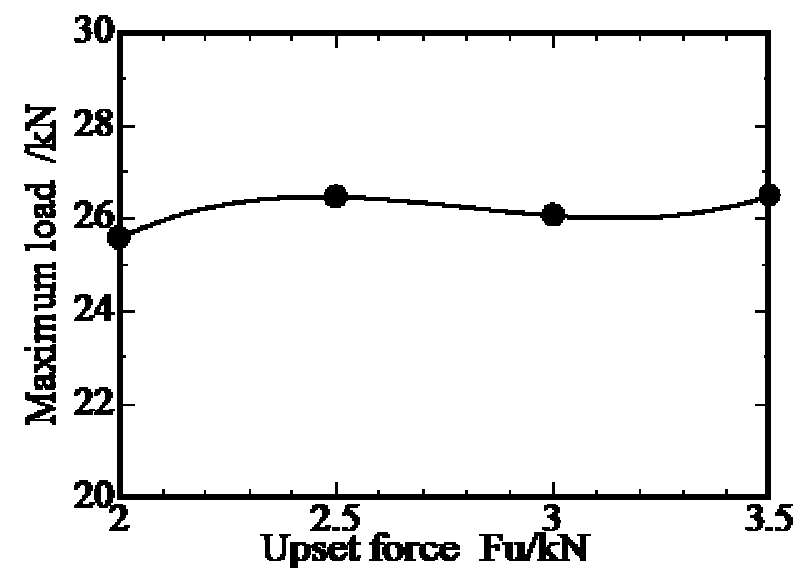

Fig.3 Relation between tensile strength and upset force

As show in the Fig.3, the maximum load of the welded joint is basically unchanged with the increase of the forging pressure. The main role of the upset pressure is extrusion the weld impurities to get forging, promote grain refinement thus improve the mechanical properties of the joints. However, due to the excessive welding heat, the grain of the joints has a tendency to grow up, therefore, joints strength lower than the base metal. 
Fig.4 Effect of friction force on the joint of deformation

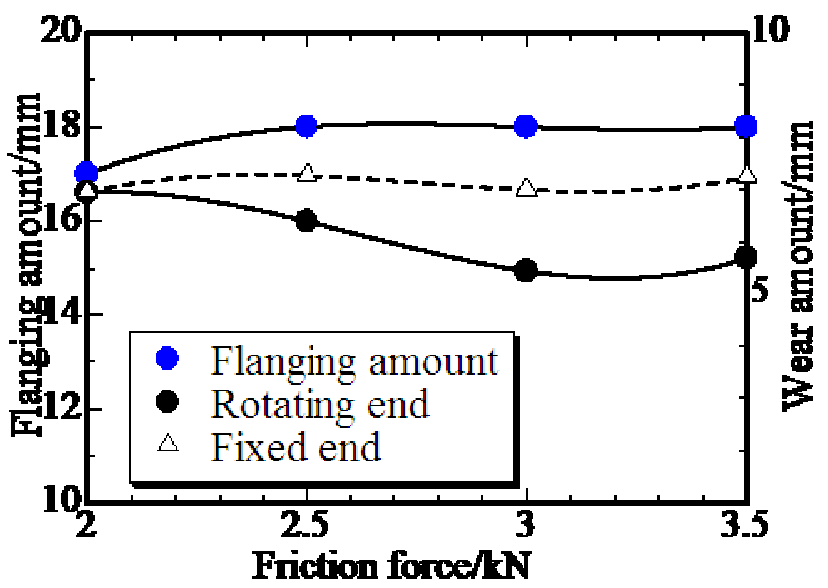

Fig. 4 and 5 show the effects of friction pressure and upset pressure on the joint of deformation, respectively. Deformation is the wear amount and flanging amount.

As shown in the Fig.4, the deformation of rotating end and fixed end is basically consistent. On the effect of friction pressure, the flanging amount is basically unchanged. In the upset is $3.5 \mathrm{kN}$, the friction changed form $2.0 \mathrm{kN}$ to $3.5 \mathrm{kN}$, welding time is $2.5 \mathrm{~s}$, the deformation of the joints are basically unchanged. In the friction pressure is $2.0 \mathrm{kN}$, upset pressure is $3.5 \mathrm{kN}$, welding time is $2.5 \mathrm{~s}$, and the amount of deformation of fixed end and flanging end is same. Due to the friction pressure is lower, the upset is larger. The heat of friction can not change the enough deformation, but the larger upset pressure causes the enough deformation. The pure is very softy. The friction pressure is $2.0 \mathrm{kN}$, can make the material generating the deformation.

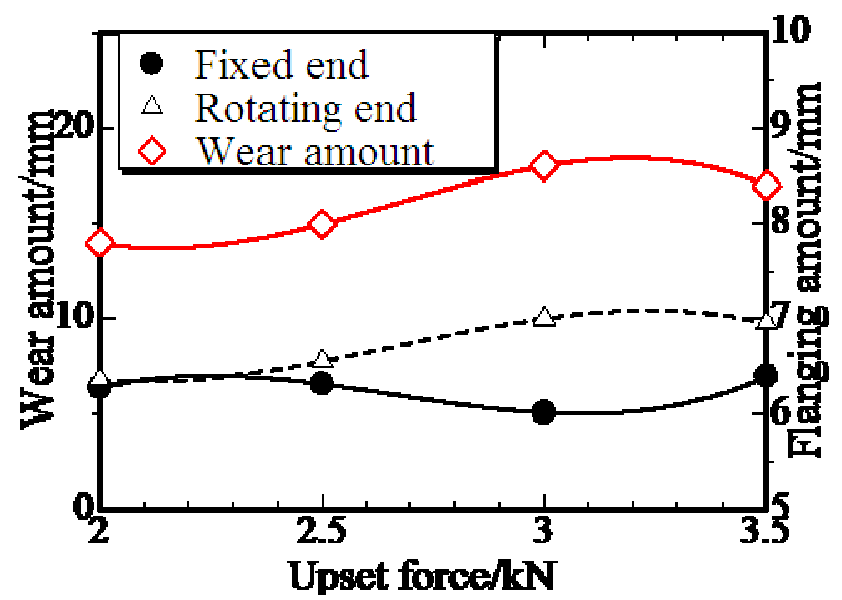

Fig.5 Effect of upset force on the joint of de formation

With the decrease of friction pressure, the wear rate decreases gradually. The friction pressure has a great influence on the joint quality. The continuous drive friction welding process is divided into four stages; initial friction, unstable friction, stable friction, stop stage. In the stable friction stage, when the friction pressure increases, the friction torque increase, friction heating power increases, the deformable layer became thinks, under the pressure to form coarse and asymmetrical flying_edge. In the stable friction stage, the mental strength is low, great plasticity, small friction coefficient, friction welding power is also stabilized in a low value. To the flanging amount, rotation end is obviously bigger than fixed end. This is mainly because the friction contact surface temperature can affect the deformation and diffusion the joints.

In the Fig.5, we can see that with the decrease upset pressure, the wear amount of the basic declined trend. The deformation of rotation end is graduate increased, the deformation of fixed end basically 
unchanged. In the upset pressure is $2.0 \mathrm{Kn}$, the deformation of the fixed end and rotating end is the same. With the upset pressure increase, the deformation of fixed end and rotating end is difference. The deformation of the fixed end and rotating end are basically the same. In the top forging force from 3.5MPa-3MPa changes, the amount of wear hardly changes, there is a slight upward trend, which shows the amount of change is not easy to wear and tear occurs in the large top forging force, mainly influenced by friction pressure. And between the $3 \mathrm{MPa}-2 \mathrm{MPa}$ changes and obvious wear volume began to decrease, indicating that when the forging force and friction pressure difference is small, the wear amount of influence material severe degeneration, contact the transfer of metal surface and start welding. Flanging amount of rotation and fixed ends are substantially the same; the friction torque effect is negligible.

\section{CONCLUSION}

(1) In this paper, continuous drive friction welding of 1060 aluminum was performed in different friction pressure and upset pressure, respectively. Mechanical properties studies show the tensile strength of joints is lower than the base mental.

(2) The joint strength at the welding time is $2.5 \mathrm{~s}$, friction pressure is $1.5 \mathrm{MPa}$ and upset pressure is $2.5 \mathrm{MPa}$ respectively, get the stable bonding, the tensile steel can get the $21.8 \mathrm{kN}$.

(3) The amount of wear and flanging amount of material is the same change trend, the flanging amount of rotation and fixed ends are different. Due to the welding parameters have an impact on the amount of deformation of material; with the friction pressure and forging pressure increases, wear of materials is more and more serious, with the increasing amount of flanging.

\section{ACKNOWLEDGEMENT}

This work was supported by the Natural Science Foundation of China (grant no. U1204520), Henan Province Foundation and Advanced Technology Research Program (grant no. 122300410202), Henan Province College \& University Youth Backbone Teachers Found Project (grant no. 2013GGS-064); Natural Science Innovation Ability Cultivating Project of Henan University of Science and Technology (2014ZCX003); National Training Programs of Innovation and Entrepreneurship for Undergraduates (201310464023) and the project sponsored by SRF for ROCS, SEM.

\section{REFERENCES}

[1] Zhongming Yang, Automobile production in dialysis welding technology of aluminum alloy, Modern Welding Technology, 2012, 12, 32-35.

[2] Y.S. Sato, A. Shiota, H. Kokawa, K. Okamoto, Q. Yang and C. Kim. Effect of interfacial microstructure on lap shear strength of strength of friction stir spot weld of aluminum alloy to magnesium alloy. Science and Technology of Welding and Joining, 2010, 15(4) 319-324.

[3] Ozdemir N. Investigation of the mechanical properties of friction-welded joints between AISI 304L, AISI Steel as a function rotational speed. Mater Lett, 2005; 59:2504-9.

[4] Honggang Dong, Lianzhen Yu, Hongming Gao, Dewei Deng, Wenlong Zhou, Chuang Dong,Microstructure and mechanical properties of friction welds between Ti-Al alloy and $40 \mathrm{Cr}$ steel rods. Transaction of Nonferrous Metals Society of China, China 24(2014) 3126-3133..

[5] YutakaS.Sato, Seung Hwan C. Park, Masato Michiuchi, et al. Constitutional liquation during dissimilar friction stir welding of Al and Mg alloys. Scripta Materialia, 2004, 50: 1233-1236. 